\title{
Telefonia Celular: Conceitos Básicos e. Fronteiras de Indefinição das Células
}

\author{
Michel D. Yacoub
}

\begin{abstract}
Este artigo traça um breve histórico das comunicações móveis e de sua evolução aos sistemas celulares, onde såo ressaltados seus principals conceitos. Mostra-se que a capacidade de tráfego pode ser melhorada com o uso de algumas técnicas de caráter global já conhecidas, mas propőe-se uma abordagem mais local, de implementação simples, cuja aplicação poderia melhorar substancialmente o desempenho do sistema. Nesta abordagem introduz-se o conceito de fronteiras de indefinição das células e alguns cálculos simples mostram que existe campo para investigações mais profundas. Trabalhos recentes são revistos, procurando-se extrair as principais conclusões sobre o estado 'da arte.
\end{abstract}

\section{Rádio Móvel}

A primeira aplicação bem sucedida de rádio móvel data do final do século XIX, quando M.G. Marconi estabeleceu o primeiro enlace de rádio entre uma estação-base terrena e um barco, num percurso de 18 milhas. Desde então, os sistemas de rádio móvel têm se desenvolvido e espalhado consideravelmente. Os departamentos de polícia, nos Estados Unidos, estão entre os que primeiro reconheceram a utilidade deste esquema de comunicação. Logo, diversas outras entidades públicas e empresas particulares (frotas de táxi, etc) começaram a operar seus próprios sistemas.

Estes primeiros sistemas consistiam de uma estação rádio base com seu transmissor e receptor instalados no topo de uma elevação. A área de cobertura objetivava ser muito grande, e apenas alguns poucos canais eram disponíveis. Como inicialmente estes sistemas eram operados manualmente, cada chamada tinha que ser encaminhada através de um operador especial de rádio móvel. Em meados dos anos 60 , os sistemas automáticos começaram a ser instalados gradualmente substituindo os operados manualmente. No entanto, apesar da automação, o usuário que tinha unæa chamada já estabelecida em uma área necessitava reiniciar a chamada ao deslocar-se para outra área.

O autor é Professor do Departamento de Comunicações da Faculdade de Engenharia Elétrica da UNICAMP, Caixa Postal 6101, 13081, Camplnas, SP. 
A demanda por serviços de rádio móvel cresceu muito rapidamente; os sistemas de então, com seus poucos canais, rudimentares protocolos de sinalização e limitada capacidade para crescimento modular não conseguiam mais sustentar tal demanda. Reclamavam-se novas idéias conceituais para tornar possivel a implementação de um sistema versátil, onde qualquer um pudesse "perambular" com seu próprio telefone e desfrutar de um serviço completo e amplamente integrado.

\section{Rádio Móvel Celular}

Estas novas idéias conceituais, hoje implementadas em sistemas de radiomóvel, foram inicialmente propostas pela Bell Telephone Laboratories, nos anos 50. Devido às limitações tecnológicas de então, tais propostas não puderam ser colocadas em prática.

O conceito básico do sistema celular é a reutilização de freqüência: se um canal de uma dada freqüência cobre uma área de raio $R$, esta mesma freqüência pode ser reutilizada em uma outra área situada a uma distância $D$ da primeira, cada área constituindo uma célula. $A$ razão $D / R$ é conhecida como razão de reutilização e constitui um importante parâmetro no arranjo das células. Células usando os mesmos canais (co-células) são posicionadas de forma que a interferência de co-canais esteja dentro de limites toleráveis; assim a razão portadora-interferência de co-canal $\left(C / I_{C}\right)$ deverá estar acima de um limiar estabelecido. Na concepção celular, a região antes servida por uma estação-base no sistema convencional é agora dividida em diversas células, cada uma com sua própria estação-base e servida por um conjunto de canais.

O formato das células não constitui um parâmetro crucial; um círculo seria a configuração óbvia, se somente os aspectos de propagação fossem levados em conta. Entretanto, um plano coberto por círculos apresentará áreas de supe rposição, ou vazios, que dificultariam o projeto do sistema, talvez tornando-o inviável. Polígonos regulares, tais como triângulos equiláteros, quadrados e hexágonos constituem bons candidatos ao formato das células. Sabe-se bem que os hexágonos regulares são o formato mais viável, principalmente por razões econômicas [1] .

O conjunto de canais disponiveis no sistema é alocado a um grupo de células que constituem o "cluster", isto é, o mesmo canal pode ser reutilizado em diferentes "clusters". O número de células num "cluster" determina o padrão de repetição, padrão que é tecido por toda a região servida pelo sistema. Devido a restrições de geometria, apenas alguns padrões de repetição podem ser implementados, sendo aqueles com 4, 7 e 12 células por "cluster" os mais comuns, Quanto menor o padrão, maior o número de canais por 
célula, isto é, mais tráfego escoado; no entanto, a distância entre co-células se torna menor, aumentado assim a interferência dos co-canais.

Alocar canais às células num "cluster" é um outro fator que contribui para a qualidade de serviço. Embora os requisitos de seletividade sejam satisfeitos pelos receptores individualmente, pode haver situações em que canais adjacentes causam interferência (interferência de canais adjacentes). Por exemplo: numa estação-base o sinal recebido de uma estação móvel transmitindo a uma grande distância pode ser prejudicado por um outro sinal transmitido por uma estação móvel próxima se os canais usados são adjacentes, existindo maior deterioração ainda na presença de desvanecimento. Uma forma de se evitar isto é impedir que se aloquem canais adjacentes numa mesma célula.

O tamanho das células varia de acordo com o planejamento da rede, feito de modo a atender certo perfil de demanda de tráfego; pode-se dizer que as células são relativamente pequenas se comparadas com os sistemas convencionais (recentes estudos sugerem o uso de freqüências em torno de $60 \mathrm{GHz}$, quando então existiriam microcélulas de $91 \mathrm{~m}$ de raio [2] ). Assim, torna-se muito comum o usuário, em seus deslocamentos. cruzar a fronteira para uma outra célula, até mesmo várias vezes. Para que haja continuidade de uma chamada iniciada numa célula $A$, cujo usuário tenha se deslocado para uma outra célula $B$, um canal em $B$ deve ser alocado a este usuário que en tão liberará o canal de $\mathrm{A}$. Este processo de troca de canais é conhecido como "handover" ou "handoff" e é feito automaticamente sem a intervenção do usuário (a interrupção da comunicação é da ordem de 400ms [3]). O "handover" ocorrerá sempre que o sinal medido na estação-base cai abaixo de um certo limiar. O processo de monitoração da qualidade do sinal, a partir do qual é possível a mudança de canais, é conhecido como "locating".

Um típico sistema de rádio móvel é mostrado na Fig. 1. As estações-base (BS, "Base Stations") servem às chamadas de e para as estações móveis localizadas em suas respectivas células. Elas se ligam aos centros de comutação móveis (MSC, "Mobile Switching Centre"), através de conexões físicas; estes centros se juntam à rede telefônica pública (PSTN, "Public Switching Telephone Network"). Os MSC's são centrais telefônicas adaptadas à telefonia celular.

Basicamente, existem duas categorias de canais: canais de controle e canais de voz. Os de controle se dividem em: (i) canais de controle dedicados (dcc, "direct control channels"); (ii) canais de "paging" (pc, "paging channels") 'e (ii) canais de acesso (ac, "access channels"). Tão logo a estação móvel entra no ar, ela varre e sin toniza o mais nítido dcc no qual se transmitem os pc's daquela área. Da mesma forma, ela agora busca o melhor pc. A seguir descreve-se sucintamente o estabelecimento de uma chamada bèm sucedida (aqui a estação móvel é a referência). 


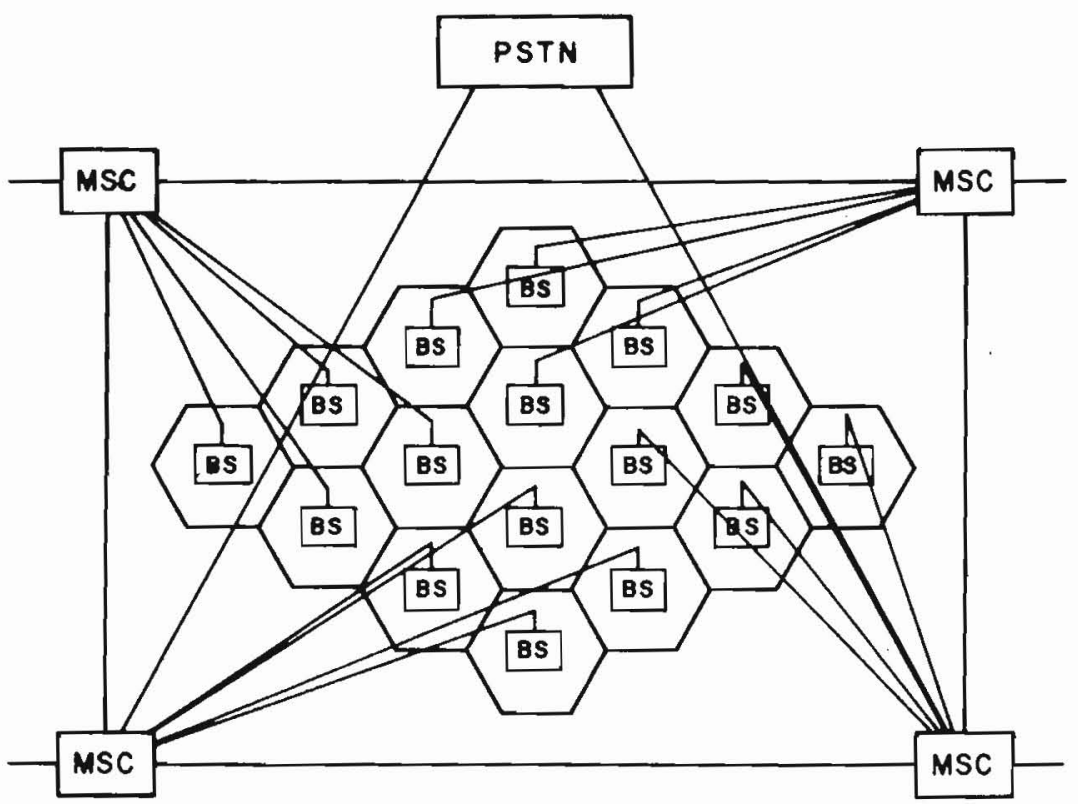

Figura 1. Um típico sistema de rádio móvel.

\section{Chamada de Saída}

A estação móvel busca e sintoniza o melhor ac entre aqueles cujos números são transmitidos pelo pc. Se a BS estiver livre, a estação móvel requisita um canal de voz cujo número é determinado e transmitido pela BS no dado ac. Este canal é então sintonizado e a chamada prossegue.

\section{Chamada de Entrada}

A PSTN roteia a chamada para o MSC em que a estação móvel está registrada. O MSC ordena às BS's que transmitam o número chamado em todos os seus pc's. A estação móvel identifica o seu número, sintoniza o ac e informa à sua BS que tal acesso é devido ao recebimento de uma chamada. Um canal de voz é alocado ao móvel onde se transmite o tom de campainha; a chamada prossegue.

\section{Especificações de Projeto de Sistema}

O sistema rádio móvel é, de uma maneira geral, especificado de forma a prover serviços condizentes com a qualidade do sistema telefônico hoje 
em uso. Em termos de tráfego, a probabilidade de bloqueio não deverá exceder $2 \%$ durante a HMM (hora de maior movimento). Em termos de transmissão, a maioria dos usuários deverá usufruir de boa qualidade de serviço por $90 \%$ do tempo; para a maioria das operadoras, "boa qualidade" significa grau 3 na classificação do CCIR [4]. Estes valores são um tanto conservadores e estão sendo reavaliados para as especificações futuras. Os assinantes preferem tolerar bloqueio maior e pior qualidade de transmissão que não ter telefonia celular de forma alguma [5] .

A maior degradação em telefonia celular é causada pela interferência de co-canal; um típico limiar da razão sinal-interferência de co-canal $\left(\mathrm{S} / \mathrm{I}_{\mathrm{C}}\right)$ é $17 \mathrm{~dB}$ [1] . A correspondente $\mathrm{C} / \mathrm{I}_{\mathrm{c}}$ (portadora/interferência de co-canal) dependerá do esquema de modulação; para modulação $\mathrm{FM}$ em faixas de $25 \mathrm{kHz}$ e $12,5 \mathrm{kHz}$, a razão $C / \mathrm{I}_{\mathrm{c}}$ requerida estaria por volta de $8 \mathrm{~dB}$ e $12 \mathrm{~dB}$, respectivamente [6].

A minima razão sinal-ruído ( $S / N$ ) é de $18 \mathrm{~dB}$. Para interferência de canal adjacente o CCIR especifica que a seletividade não deve ser inferior a $70 \mathrm{~dB}$ [4]. É importante salientar que embora freqüentes "handovers" causem perturbação, não existem especificações para limitar o número máximo e nem a duração máxima dos mesmos.

Sistemas diferentes possuem suas próprias especificaçōes. O sistema AMPS ("Advanced Mobile Phone Service"), usando FM de $30 \mathrm{kHz}$, requer que a $\mathrm{S} / \mathrm{I}_{\mathrm{c}}$ exceda $17 \mathrm{~dB}$ em $90 \%$ da área [1]. O TACS ("Total Access Communication System"), usando $F M$ de $25 \mathrm{kHz}$, requer $\mathrm{C} / \mathrm{I}_{\mathrm{c}} \geqslant 7 \mathrm{~dB}$ em $99 \% \mathrm{da}$ área [3] . O GSM ("Groupe Spéciale Mobile"), um sistema da segunda geração, usará modulação digital GMSK ("Gaussian Mininum Shift Keying') e especifica $\mathrm{C} / \mathrm{I}_{\mathrm{c}} \geqslant 7 \mathrm{~dB}$ em $90 \%$ da área [7]; em termos de probabilidade de erro o objetivo é que esta não exceda $10^{-2}$.

\section{Técnicas de Melhoria de Desempenho de Tráfego}

Apesar de se encontrar em pleno funcionamento nos países desenvolvidos e estar se espalhando por todo o mundo, a telefonia celular era há pouco tempo considerada um luxo; o mercado de negócios constituía a maior parte dos seus usuários. Embora o preço ainda seja alto, a demanda por serviços celulares está em vertiginoso crescimento. Qualquer previsão de expansão é logo ultrapassada [8]. Desta forma, muitas áreas já operam na região de saturação. Prevê-se que o aspecto limitante na expansão do mercado é mais técnico do que relativo a custo [9]. Conseqüentemente, várias técnicas de melhoria da capacidade do sistema têm sido propostas e as principais delas são brevemente descritas aqui. 


\subsection{Uso de Antenas Direcionais}

Seguindo os mesmos princípios que levaram o sistema convencional a evoluir para o celular, a divisão da célula tem por ojetivo aumentar a capacidade da rede. Reduzindo-se o tamanho das células haverá mais células por área, mais canais em tais áreas e conseqüentemente mais tráfego escoado. $\mathrm{A}$ Fig. 2 mostra um exemplo desta técnica; as células $A, B$ e $C$ constituem o sistema antes da divisão e $E, F$ e $G$ são as células geradas pela divisão.

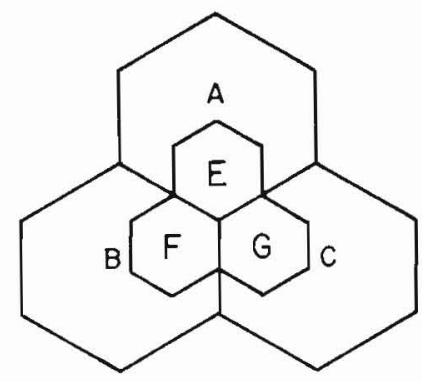

Figura 2. Um exemplo de divisão de célula.

Teoricamente este processo pode ser feito sempre que necessário. Na prática, entretanto, existem limitações:

(i) como a distância entre as células se reduz, isto resulta numa maior interferência de co-canal, embora se mantenha o mesmo padrão de repetição;

(ii) encontrar um local para a estação-base pode se tornar uma tarefa difícil já que as tolerâncias ficam cada vez menores;

(iii) o custo total do sistema aumenta com o aumento do número de estações-base.

O uso de antenas direcionais é uma alternativa para a técnica de divisão dè células com as vantagens de ser mais viável em temos de custo [10] e [11] e diminuir a interferência de co-canal [10] e [12]. Neste método cada célula é dividida em setores (mais comumente 3 ou 6 setores), sendo que cada setor agora é considerado uma nova célula. A Fig. 3 ilustra como um arranjo de 3 setores é equivalente a dividir a célula em 3 outras.

\subsection{Algoritmos de Alocação de Canais}

O uso eficiente dos canais determina o bom desempenho do sistema e pode ser obtido por diferentes técnicas de alocação. Uma grande quantidade de 


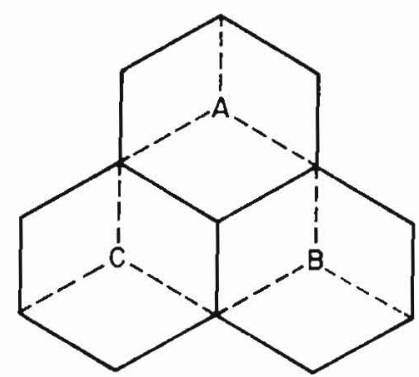

Figura 3. Uso de antenas direcionais de $120^{\circ}$.

investigações [13] - [18] mostra que existe um considerável aumento na ocupação dos canais quando determinadas técnicas de alocação são aplicadas. As principais técnicas são sucintamente descritas a seguir.

\section{(i) Alocação Fixa de Canais}

Nesta técnica os canais disponíveis são divididos entre as células do "cluster" de acordo com a demanda determinada por um dado perfil de tráfego. Se este perfil é bem conhecido, a alocação pode ser otimizada para oferecer o melhor desempenho. No entanto, qualquer variação repentina no perfil de tráfego pode levar o sistema a um colapso.

\section{(ii) Alocação Dinâmica de Canais}

Este algoritmo, de fato, engloba um grande número de estratégias com a característica comum de todos os canais do sistema estarem disponiveis para todas as células; a alocação é feita de acordo com a demanda dinâmica dos usuários. Isto faz com que o sistema se adapte a variações na distribuição espacial de tráfego, mas dá maus resultados para alta carga [14] e [19].

\section{(iii) Alocação Híbrida de Canais}

Esta técnica é uma combinação das duas anteriores; cada célula tem uma pofcentagem de canais fixos enquan to que o restante dos canais é manuseado dinamicamente. $O$ desempenho do sistema dependerá da distribuição de tráfego e também da razão de canais com alocação fixa para os com alocação dinâmica [17].

\section{(iv) Alocação de Canais por Empréstimo}

Aqui, a célula que tiver todos os seus canais ocupados procurará um canal livre na célula vizinha; caso não haja nenhum, a chamada é bloqueada. É possivel melhorar esta técnica "forçando-se" o empréstimo da célula adjacente, que estando bloqueada forçará o empréstimo de outra célula vizinha, e assim por diante [20].

Nos sistemas celulares atuais apenas a alocação fixa encontra-se implementada. 


\subsection{Fronteiras de Indefinição das Células}

A implementação de qualquer uma das técnicas de alocação descritas (com exceção da fixa) implica um total envolvimento da unidade de controle de processamento central com cada chamada tendo de ser manipulada por esta unidade.

É possivel, no entanto, considerar-se uma abordagem mais local com as decisōes sendo tomadas não centralizadamente mas talvez no próprio MSC. Se existir tráfego disponível para roteamento alternativo entre células adjacentes, então o gerenciamento pode ficar na correspondente área de serviço, já que seria uma questão de se determinar quanto do tráfego a ser roteado deve ser encaminhado para cada célula. Este é o obje to de um longo trabalho de pesquisa desenvolvido pelo autor [21] - [23] e que será apenas introduzido neste artigo. As investigações mais detalhadas serão reportadas em outros artigos. A abordagem mais local aflora do conceito de fronteiras de indefinição das células, onde se considera o limiar de tolerância permitida entre caminhos de rádio para duas ou mais estações-base e que será detalhado a partir da Seção 6.

\section{Revisão da Literatura}

Como muitos outros aspectos das comunicações móveis, via rádio, o conceito de fronteiras de indefinição das células envolve tanto teoria de propagação quanto de tráfego. Muito pouco foi feito neste campo no que concerne às fronteiras de indefinição e os artigos [24] e [25] tratam as duas áreas separadamente.

De fato, nos estudos de propagação [25], as fronteiras de indefinição aparecem como um subproduto da investigação principal sobre o uso de um banco de dados topográficos para o planejamento de abocação de freqüências de um sistema de rádio móvel. Os resultados destes estudos são dados em forma de um mapa pictorial onde se mostram os níveis de potência dos sinais nas células e conseqüentemente as áreas de interseção podem ser vistas (áreas comuns servidas por duas ou três estações-base).

Lorenz [25] apresenta um algoritmo de predição de propagaçao baseando-se na orografia e na categoria do terreno (área construída, área aberta ou água). Os resultados foram comparados com testes de campo sendo que os erros apresentaram distribuição Gaussiana com valor médio não superior a $2 \mathrm{~dB}$ e desvio padrão variando de acordo com a orografia. De uma figura mostrada em [25] pode-se verificar que as áreas de cobertura das células se sobrepõem perto de suas fronteiras e que $50 \%$ da área de cobertura correspondem à interseção entre duas células vizinhas, e $30 \%$ entre três 
células para uma tolerância de $8 \mathrm{~dB}$ entre os caminhos de rádio às estaçõesbase. Isto significa que $50 \%$ dos usuários podem ter acesso a pelo menos duas estações-base e $30 \%$ a pelo menos três estações, se considerarmos uma distribuição uniforme dos usuários pela área de cobertura.

Nas considerações de tráfego [24], as fronteiras de indefinição são mencionadas mais claramente e uma estratégia bem simples (Retentativa Direcionada) é analisada por Eklundh [24]. Esta técnica já se encontra implementada em alguns sistemas (por exemplo, o TACS da Inglaterra) e será também usada no sistema Pan Europeu. Ela consiste em direcionar uma chamada para outra célula vizinha (caso o usuário possa se comunicar com a correspondente estação-base e esta tenha canais livres) na ocorrência de bloqueio em sua própria célula.

Eklundh usou um modelo analítico e outro com simulação de Monte Carlo. Os resultados correspondentes foram então comparados. No modelo analítico, uma estrutura de 7 células foi usada como base para um sistema de "gradings" interligados, onde, através de um arranjo de realimentação, um número "infinito" de células é reproduzido. No modelo de simulação, uma estrutura de $20 \times 20$ células foi usada, e as medidas tomadas na célula central. Ambos os modelos consideraram distribuição uniforme de tráfego e os resultados correspondentes apresentaram uma boa concordância. Mostrou-se que para um exemplo particular de 10 canais por célula e com $50 \%$ do tráfego acessando pelo menos duas células, o aumento na capacidade total do sistema é da ordem de $20 \%$. Por outro lado, os usuários que só se comunicam com sua própria estação-base sofrem uma degradação de serviço (aumento da probabilidade de bloqueio em sua célula).

\section{Rádio Móvel e as Fronteiras de Indefinição das Células}

Muitos aspectos do projeto e do desempenho de telefonia celular são estuda. dos na hipótese de células com fronteiras fixas. Na prática, as fronteiras das células são incertas e variantes porque a propagação de ondas radioelétricas varia no tempo e no espaço. Os procedimentos de "handovers" levam isto em consideração e se baseiam normalmente nos níveis relativos dos sinais da estação móvel para duas estações-base. No entanto, em geral, - planejamento e o projeto do sistema não são otimizados para a situação prática em que as fronteiras são indefinidas e as áreas de serviço das estações-base se sobrepõem.

Se uma estação móvel estiver perto da fronteira da célula, poderá ter uma comunicação adequada com mais de uma estação-base. E possível usar esta propriedade como base para técnicas de roteamento alternativo, à luz 
de informações tais como a ocupação atual dos canais em cada célula, e o tráfego médio ou previsto em cada célula de forma a maximizar a capacidade de tráfego conjunta de um arranjo de células.

O primeiro passo na avaliação de estratégias de roteamentos alternativos é a estimativa da proporção de tráfego que possa razoavelmente ser tratado como disponivel para roteamento alternativo. Isto será explorado em profundidade em outros artigos mas pode-se ter uma idéia aproximada a respeito usando-se uma simples análise de geometria.

\subsection{Estações Móveis com Dois Caminhos: Uma Estimativa Grosseira}

O formato hexagonal das células num sistema de rádio móvel é considerado apenas como um modelo ideal; não pode ser obtido na prática. Se antenas omnidirecionais são usadas, então a área de cobertura pode ser aproximada por um círculo. Num arranjo de células hexagonais, se cada célula for superposta por um círculo (ver Fig. 4) aparecerão áreas comuns que de fato representam regiões sendo servidas por duas estaçōes-base.

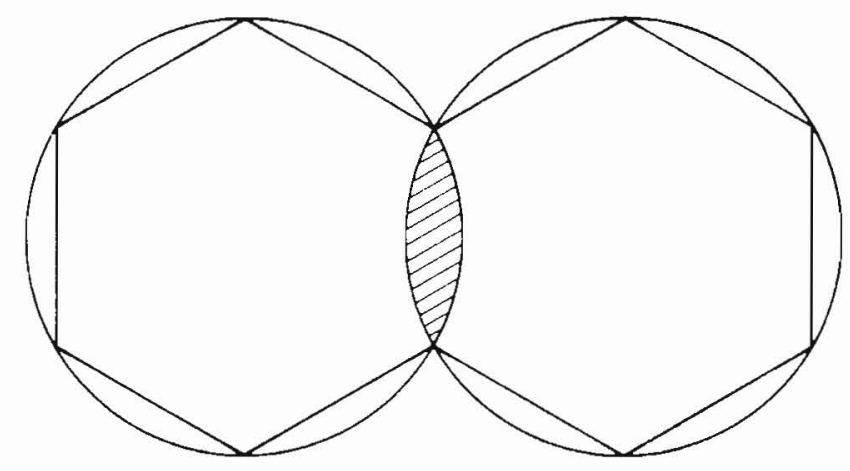

Figura 4. Áreas comuns entre duas células adjacentes.

Representa-se por $y$ a razão entre a área comum e a área total de um célula hexagonal. A área comum é aquela da interseção entre uma célula hexagonal correspondente a uma dada estação-base e a união de seis círculos correspondentes a seis outras estações-base vizinhas. Tem-se assim

$$
\gamma=\frac{\text { área comum }}{\text { área total }}
$$

Da relação acima, $\gamma$ é obtido como aproximadamente $21 \%$. Supondo-se uma distribuição uniforme das estações móveis dentro da célula conclui-se que 
$21 \%$ das mesmas estão nas regiões de indefinição podendo ser servidas por ambas as estações-base.

Mesmo que fosse concebível, não há interesse ou vantagem, em termos do desempenho do sistema, em se fazer as fronteiras entre células completamente rígidas, isto é, a área de cobertura de uma estação-base começando exatamente no ponto em que a servida pela estação-base vizinha termina. Uma região comum deve ser planejada de forma a se permitir "handovers" seguros, ou seja, deve haver uma certa flexibilidade para a continuidade das chamadas das estações móveis cruzando a fronteira entre células. Esta área flexível assegura ao sistema uma adaptabilidade prática às condições em que não possam ocorrer "handovers" de imediato (por exemplo, quando não existem canais livres na célula de chegada, ou quando alguma outra tarefa de maior prioridade estiver sendo tratada no momento do pedido, etc).

Considere duas células hexagonais adjacentes cada uma de raio $\mathrm{R}$ e com contorno hexagonal de "handover" de raio $r$, conforme mostra Fig. 5 (o contorno hexagonal de "handover" é usado apenas por simplicidade). Definese um fator de penetração $p$ como a proporção do raio da célula correspondente à região na qual o "handover" se faz com segurança, ou seja,

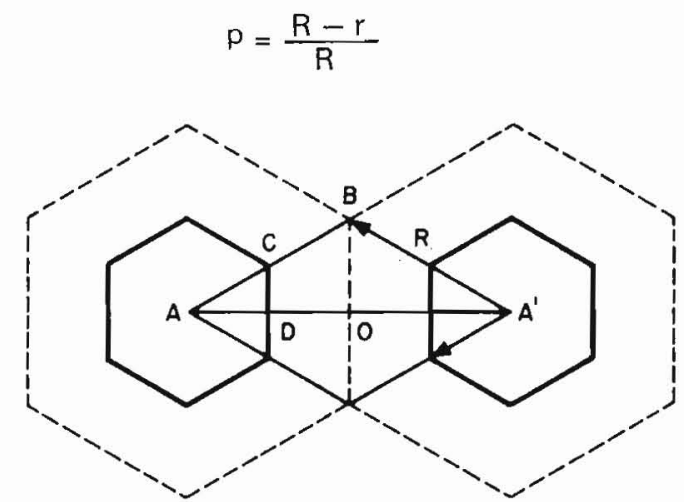

Figura 5. Duas células adjacentes e seus contornos de "handover".

Por causa da simetria, apenas $1 / 12$ do hexágono é explorado. Assim, o paràmetro $\gamma$ definido em (1) se escreve agora

ou seja

$$
\gamma=\frac{\text { área } \mathrm{ODCB}}{\text { área } \mathrm{AOB}}
$$

$$
\gamma=(2-p) p
$$


A variação de $\gamma$ com o fator de penetração $p$ é mostrada na Fig. 6. Pode-se ver que um fator de penetraçao de $20 \%$ fornece $36 \%$ de área comum, ou seja, supondo-se distribuição uniforme das estações móveis tem-se que $36 \%$ do tráfego pode ser considerado como flexível.

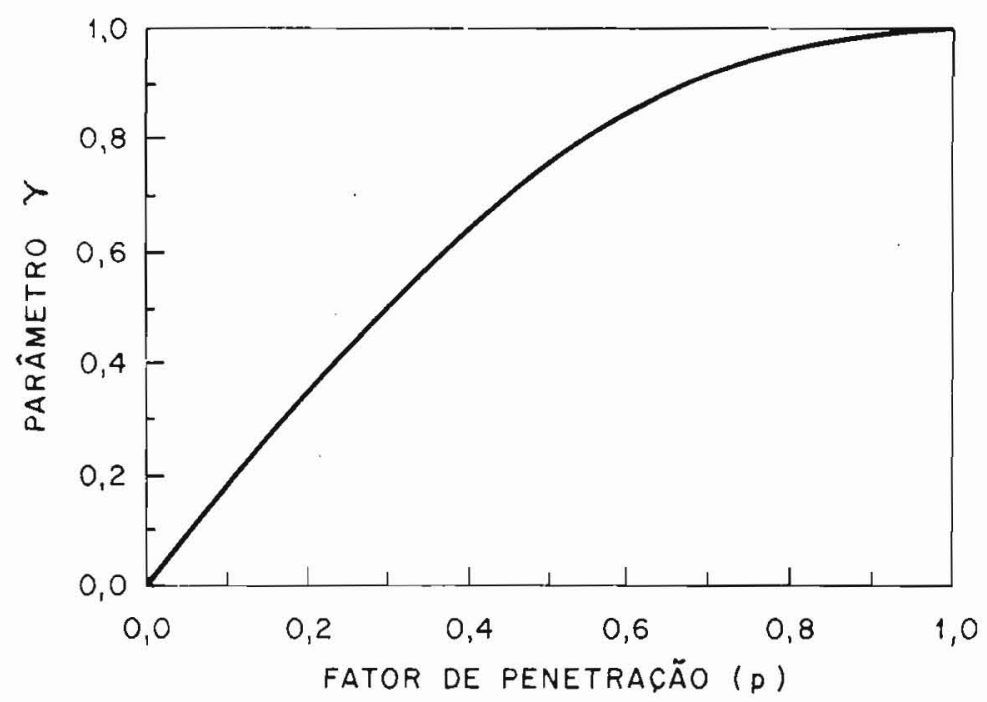

Figura 6. Proporção de área comum (2 caminhos) versus fator de penetração.

\subsection{Benefícios Potenciais do Roteamento Alternativo em Duas Célu- las Contíguas}

Para se avaliar a potencialidade de uma adaptação local, são considerados dois casos ex tremos relativamente à situação em que há duas células hexagonais contíguas.

(a) Fronteiras totalmente fixas $(\gamma=0)$ : as células estão completamente isoladas uma da outra, isto é, tão logo a estação móvel cruza a fronteira deverá ocorrer um "handover".

(b) Fronteiras totalmente flexíveis $(\gamma=1)$ : as duas células podem ser consideradas como uma única com as estações móveis tendo total acesso aos canais de amnas as células.

As duas situaçōes são ilustradas ha Fig. 7. 


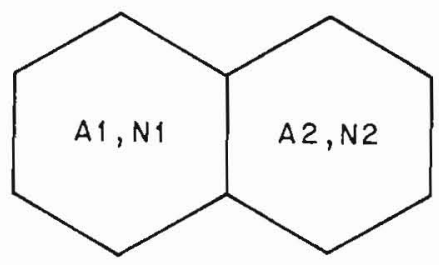

(a) Flexibilidade nula

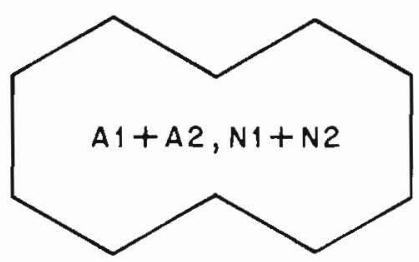

(b) Flexibilidade total

Figura 7. Dois casos extremos de fronteiras de indefinição.

Se $A_{1}, N_{1}$ e $A_{2}, N_{2}$ são tráfego e número de canais nas células 1 e 2 , respectivamente, e $B_{a}$ e $B_{b}$ as probabilidades de bloqueio nos casos (a) e (b), respectivamente, tem-se

$$
\begin{aligned}
& B_{a}=\frac{A_{1} E\left(A_{1}, N_{1}\right)+A_{2} E\left(A_{2}, N_{2}\right)}{A_{1}+A_{2}} \\
& B_{b}=E\left(A_{1}+A_{2}, N_{1}+N_{2}\right)
\end{aligned}
$$

onde $E(A, N)$ é a probabilidade de bloqueio dada pela fómula $B$ de Erlang.

Sabe-se que $B_{b}<B_{a}$ para $A_{1}, N_{1}$ ou $A_{2}, N_{2} \neq 0$. Apenas como um exemplo prático considere $A_{1}=4$ Erlang, $N_{1}=5, A_{2}=1$ Erlang, $N_{2}=5$. Neste caso particular, tem-se $B_{a}=16 \%$ e $B_{b}=1,8 \%$.

Obviamente, estes são casos extremos, não aplicáveis a uma situação realística. Na prática, a proporção de sobreposição de áreas $(\gamma)$ estará entre estes extremos. É importante, no entanto, determinar os limites inferior e superior, apenas para estimar quanta melhora se pode obter. Por outro lado, não é necessário ir tão longe na análise de situações irreais. Considere, por exemplo, o mesmo sistema de duas células, com a mesma razão de tráfego, mas agora com uma flexibilidade de $37,5 \%$, isto é, esta é a proporção de tráfego em cada célula (portanto no sistema) disponível na região da fronteira para ser roteada para uma ou outra célula. Isto é mostrado na Fig. 8, onde os números correspondem ao tráfego na célula 1 , na fronteira e na célula 2.

Se 0 tráfego flexivel for direcionado para a célula 2, o sistema recuperará a condição de balanceamento com cada célula escoando 2,5 Erlang. O bloqueio médio então cai para $7 \%$. Apesar do balanceamento, é possível ainda uma melhora do desempenho se a condição de bloqueio das células for conhecida: se uma célula estiver bloqueada então $37,5 \%$ do tráfego $(1,875$ Erlang) poderá ser direcionda para a célula não bloqueada. 


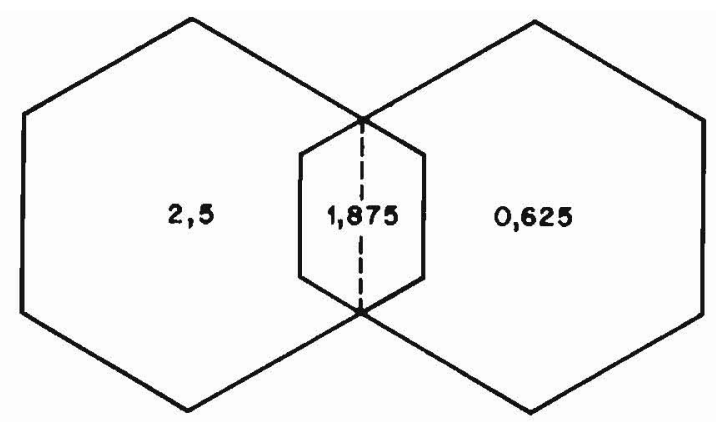

Figura 8. Sistema com duas células e $37,5 \%$ de tráfego flexivel.

\subsection{Estações Móveis com T rês Caminhos: Uma Estimat iva Grosseira}

Os benefícios de se ter tráfego flexível para roteamento alternativo são evidentes: os picos locais podem ser achatados pela transferência do tráfego para fora da região de congestionamento. Quanto mais células acessíveis mais adaptável o sistema será.

O simples formato hexagonal das células provê um arranjo onde a seguinte investigação pode conduzir à maior acessibilidade de células acima mencionada: o que acontece com as estações móveis situadas perto da junção das três células? É inteiramente plausível que tais estações possam ter comunicação adequada com as respectivas três estações-base. Existe tráfego suficiente para o roteamento alternativo? Considere três células hexagonais adjacentes cada uma delas de raio $\mathrm{R}$, e com contorno hexagonal de "handover" de raio $r$, conforme mostra a Fig. 9.

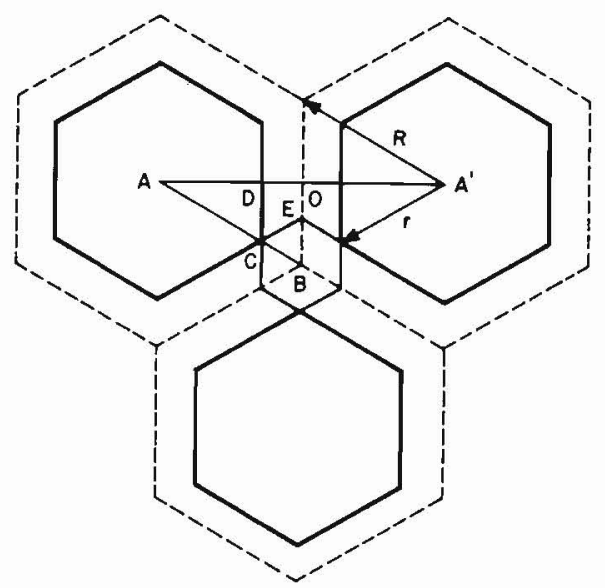

Figura 9. Três células adjacentes e seus contornos de "handover". 
Pode-se notar que se existem regiões de sobreposição, grande parte delas compreende uma interseção de regiões definidas pelos contornos de "handover" das três células. Defini-se $\delta$ como sendo a proporção de rádios móveis com três ou mais caminhos. Assim, da Fig. 9 e tirando-se vantagem da geometria hexagonal, obtém-se

$$
\delta=\frac{\text { área } B C E}{\text { área } A O B}
$$

De simples geometria, obtém-se

$$
\delta=2 p^{2}
$$

cuja validade é para $0 \leqslant p \leqslant 0.5$, ou, equivalentemente, $0 \leqslant R-r \leqslant R / 2$. Para $p>0.5$, o segmento de reta CE corta $A A^{\prime}$ e a área acima de $A A^{\prime}$ deve ser subtraída do triângulo BCE. Isto é ilustrado na Fig. 10. Agora tem-se

$$
\delta=\frac{\text { área } \mathrm{BCFO}}{\text { área } \mathrm{AOB}}=\frac{\text { área } \mathrm{BCE}-\text { área } \mathrm{FOE}}{\text { área } \mathrm{AOB}}
$$

resultando

$$
\delta=1-2(1-p)^{2}
$$

que é válida para $0,5 \leqslant p \leqslant 1$, ou, equivalentemente, para $R / 2 \leqslant R-r \leqslant R$.

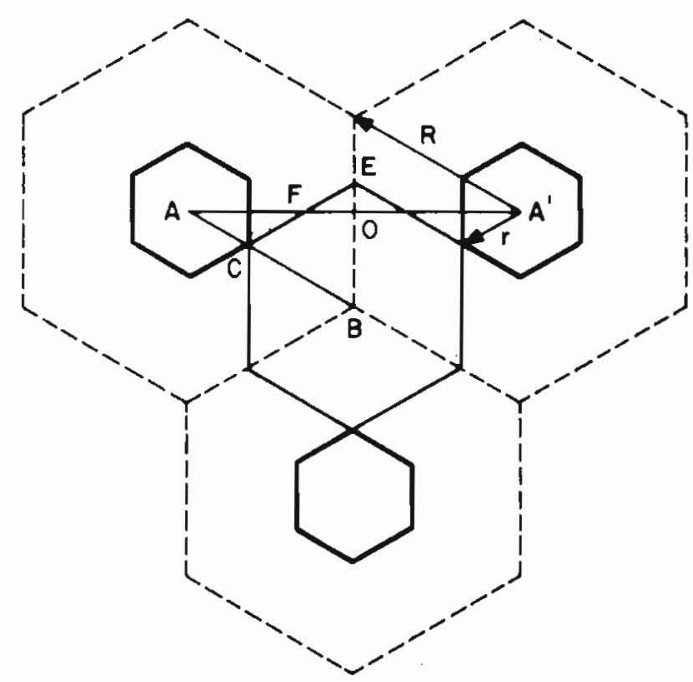

Figura 10. Áreas comuns para $p>0,5$.

Revista da Sociedade Brasileira de Telecomunicaçőes 
A variação de $\delta$ com o fator de penetração $p$ é mostrada na Fig. 11.

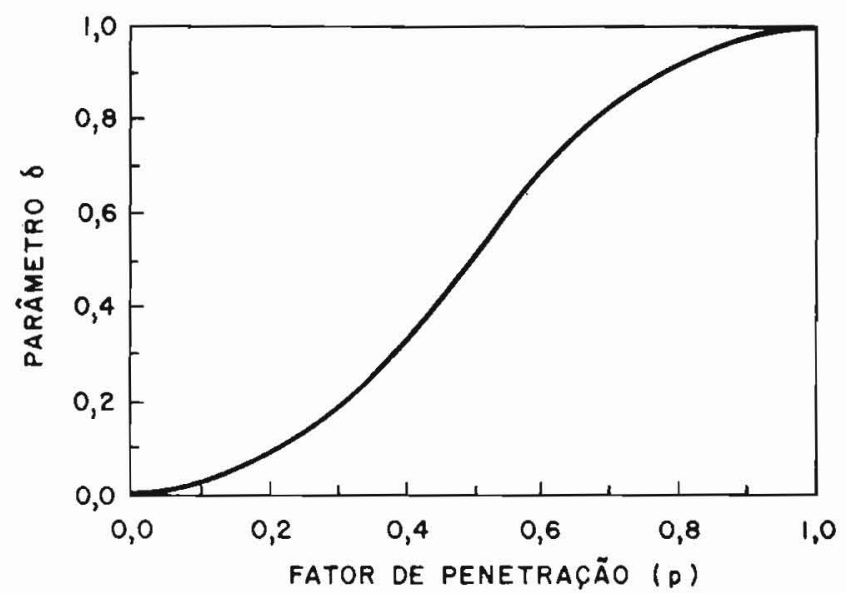

Figura 11. Proporção de área comum ( 3 ou mais caminhos) versus fator de penetração.

Um aspecto interessante a se investigar é a relação entre a proporção de tráfego com três ou mais caminhos alternativos $(\delta)$ e aquela com dois ou mais caminhos alternativos $(\gamma)$. Esta relação pode ser facilmente obtida de (2) e (3), resultando

$$
\begin{aligned}
& \delta=2(1-\sqrt{1-\gamma})^{2}, \quad 0 \leqslant p \leqslant 0,5 \text { ou } 0 \leqslant \gamma \leqslant 3 / 4 \\
& \delta=-1+2 \gamma, \quad 0,5 \leqslant p \leqslant 1 \text { ou } 3 / 4 \leqslant \gamma \leqslant 1
\end{aligned}
$$

É possível mostrar que de fato esta é ainda uma subestimativa [23] para $\delta$. Uma melhor aproximação, embora ainda subestimada, seria

$$
\delta \cong \gamma^{2}
$$

Curvas de $\delta$ em função de $\gamma$ comparando (4) e (5) são apresentadas na Fig. 12.

6.4. Benefícios Potenciais do Roteamento Alternativo para Três Células Contíguas

Ao se trabalhar com trẽs células, a questão que surge é se vale ou nāo a pena fazer-se uso da opção do terceiro caminho. Considere um sistema com a distribuiçảo de tráfego mostrada na Fig. 13. 


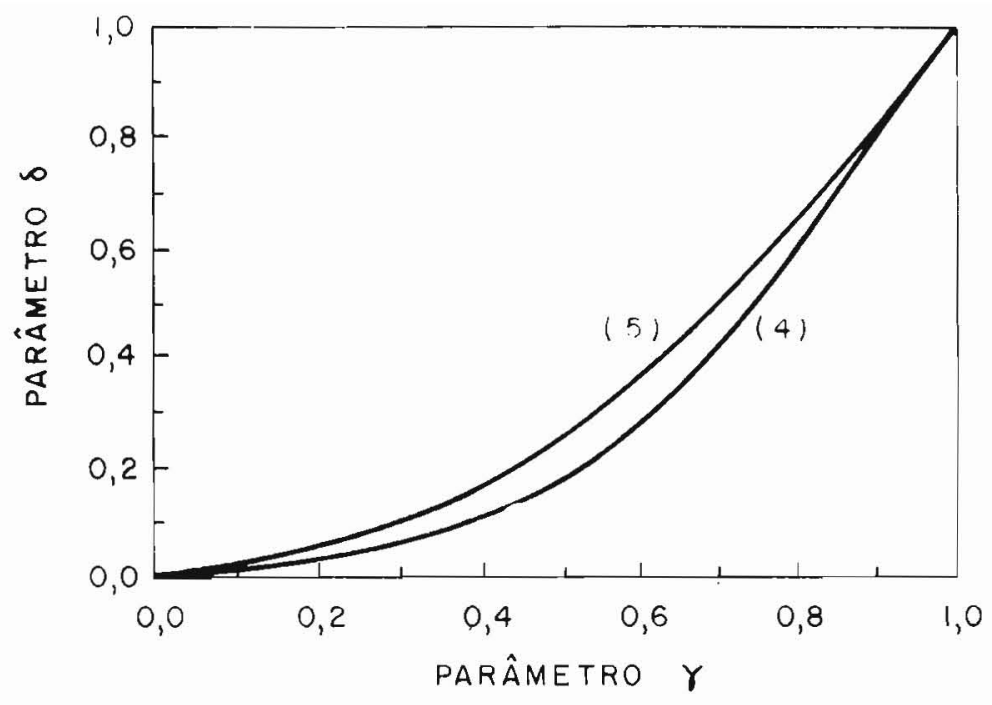

Figura 12. Proporção de área comum com 3 ou mais caminhos em função da proporção de área comum com 2 ou mais caminhos.

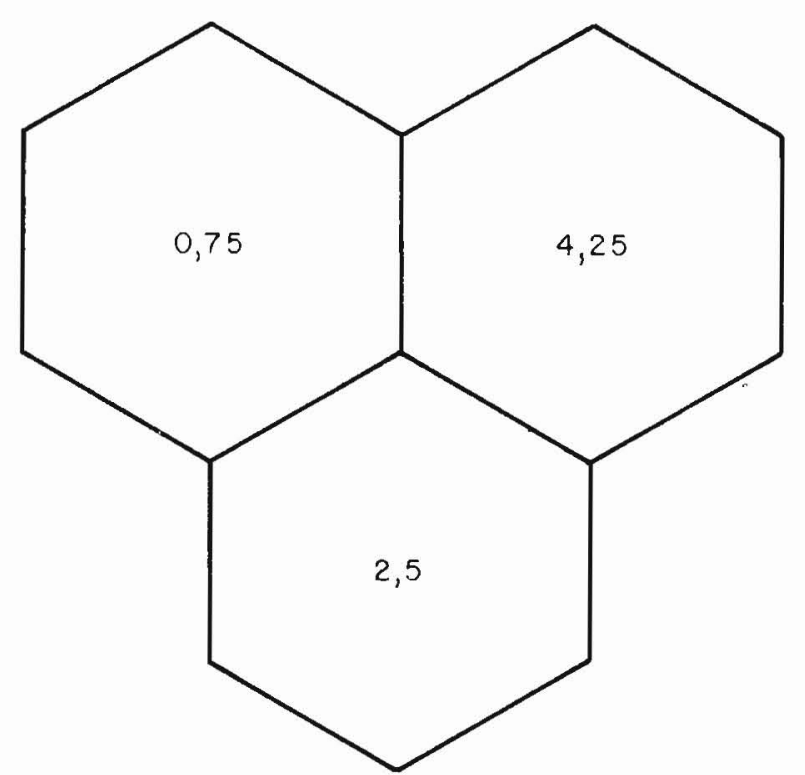

Figura 13. Um exemplo de um sistema de 3 células com uma particular distribuição de tráfego.

Revista da Sociedade Brasileira de Telecomunicaçס̃es 
Se se admite uma flexibilidade de $45 \%$ relativamente às duas células adjacentes e supõe-se que o tráfego adaptável está igualmente distribuído entre suas duas fronteiras relevantes, então tem-se a distribuiçao mostrada na Fig. 14.

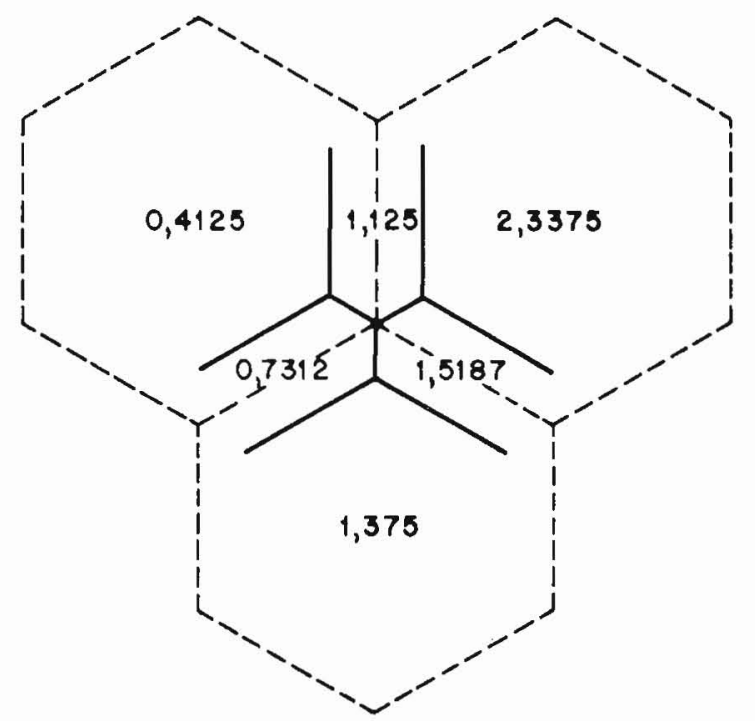

Figura 14. Tráfego adaptável com dois caminhos para uma flexibilidade de $45 \%$.

Neste caso tem sido suposto que o controle do sistema não reconhece o possível terceiro caminho. Se $\gamma$ é a proporção de tráfego com 2 ou mais caminhos, $\delta$ é a proporção com 3 ou mais, então $\gamma-\delta$ dá a proporção com 2 caminhos apenas. Supondo válida a aproximação em (5), a distribuição de tráfego é agora aquela mostrada na Fig. 15. Pode-se ver que se o tráfego flexivel for convenientemente redistribuído entre as células, o sistema esquematizado na Fig. 15 recuperará a condição de balanceamento, enquanto que no caso considerado na Fig. 14 isto não ocorrerá.

De fato, uma considerável melhoria pode ser alcançada se a condiçao de bloqueio das células for levada em consideração, já que $20,25 \%$ do tráfego total (correspondente ao tráfego com uma terceira opção) terá acesso a uma célula livre quando as duas outras estiverem bloqueadas.

\section{Conclusões}

Comunicações móveis têm sido usadas desde os princípios da invenção do rádio e o conceito celular é bastante antigo. No entanto, só mais recente- 


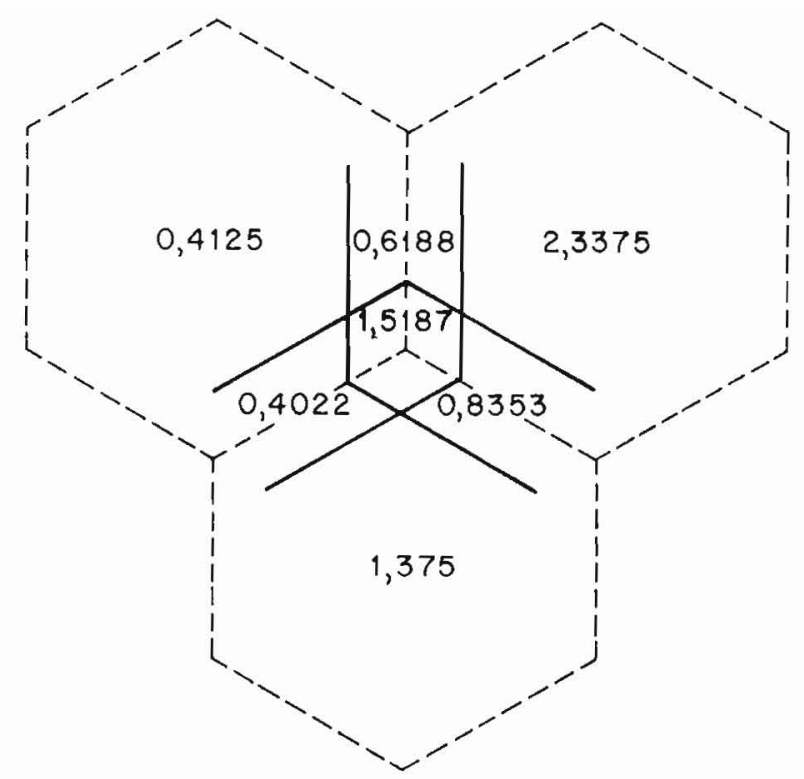

Figura 15. Tráfego adaptável com 2 e 3 caminhos para uma flexibilidade de $45 \%$.

mente, com a disponibilidade de recursos tecnológicos, é que sistemas celulares têm sido implementados.

Apesar de sua "juventude", sistemas de rádio móvel celular já se encontram bastante espalhados e seu mercado, ainda liderado pelo de negócios, está experimentando um crescimento vertiginoso, com todas as previsões de crescimento sendo ultrapassadas.

Para suportar tal demanda, várias técnicas de melhoria de desempenho têm sido investigadas, embora muito poucas aplicadas. Em geral estas técnicas implicam substancial modificação no "hardware" e "software" do sistema ou um completo replanejamento do padrão de reutilização de freqüências.

Este artigo sugere que com uma abordagem mais local é ainda possível conseguir um aumento global do desempenho do sistema celular. A idéia é baseada no fato de que estaçōes móveis próximas à fronteira entre células podem comunicar-se adequadamente com mais de uma estação-base. É possível, então, escolher-se a mais conveniente estação-base, de forma que a capacidade conjunta de tráfego possa ser melhorada. Embora isto implique algumas mudanças do padrão de utilização dos canais, todos os canais estarão dentro de suas áreas de serviço, ou adjacentes às mesmas, de forma que não haverá sérias implicaçōes para o padrão de reutilização de freqüências.

Revista da Sociedade Brasileira de Telecomunicaçðes 
Além disso, embora alguma mudança no algoritmo de "handover" e roteamento inicial seja necessária, as comparações e rearranjos são puramente locais e não envolvem nenhuma técnica complexa para o gerenciamento global do sistema.

Poucos estudos foram feitos nesta área, mas suficientes para mostrar que - campo é potencialmente atrativo: "as áreas comuns nas fronteiras são um tanto grandes" [25] ; supondo que exista uma probabilidade de superposição de áreas de serviço, uma técnica bem simples mostrou que "um ganho substancial pode ser obtido" [24].

\section{Agradecimentos}

O autor deseja agradecer ao Professor K.W. Cattermole pela valiosa colaboração no trabalho conjunto desenvolvido na Universidade de Essex, Inglaterra, à CAPES por ter tornado possivel este trabalho, ao CNPq por propiciar a continuação do mesmo na UNICAMP e finalmente ao CPqD-Telebrás, pelo interesse em introduzir pesquisas neste campo (Contrato 208/87 celebrado com a UNICAMP).

\section{Referências}

[1] "Advanced Mobile Phone Services", Special Issue, Bell System Technical Journal, vol. 58, n. 1 , Janeiro 1979.

[2] R. Steele e V. K. Prabu, "High-User-Density Digital Cellular Radio Systems", Proceedings of the IEE, Parte F, vol. 132, n. 5 , Agosto 1985, pp. 396-404.

[3] C. J. Hughes e M. S. Appleby, "Definition of a Cellular Mobile Radio System", Proceedings of the IEE, Parte F, vol. 132, n. ${ }^{\circ} 5$, Agosto 1985, pp. 416-424.

[4] Relatório CCIR 358-4, XV Assembléia Plenária, Dubrovnik 1986, vol. VIII.

[5] J. Hoff, "Mobile Telephony in the Next Decade", Second Nordic Seminar on Digital Land Mobile Radio Communication, Stockholm, Suécia, Outubro 1986, pp. 142-145.

[6] R. C. French, "The Effect of Fading and Shadowing on Channel Reuse in Mobile Radio", IEEE Transactions on Vehicular Technology, Agosto 1979, pp. 171-181. 
[7] Comunicação pessoal com membros do quadro da British Telecom Research Laboratories.

[8] W. C. Y. Lee, "Mobile Communications Engineering", McGraw Hill, New York, 1982.

[9] U. Johanson, "The Best is Yet to Come", Communications Systems World wide, Outubro 1987.

[10] S. Heeralall, "The Applications of Directional Antennas in Cellular Mobile Radio Systems", Ph.D. Thesis, University of Essex, Inglaterra, Setembro 1988.

[11] "Land Mobile Radio System", R. J. Holbeche (editor), IEE Telecommunications Series, vol. 14, Peter Peregrinus, Londres, 1985.

[12] W. C. Y. Lee, "Elements of a Cellular Mobile Radio System", IEEE Transactions on Vehicular Technology, vol. VT-35, n. 2, Maio 1986, pp. 48-56.

[13] B. Arazi, "New Channel Assignment Strategy in Cellular Mobile Radio Communication Systems", IEE Proceedings, vol. 133, Parte F, n. 6 , Outubro 1986 , pp. 569-575.

[14] D. C. Cox e D. O. Reudink, "A Comparison of Some Channel Assignment Strategies in Large-Scale Mobile Communications Systems", IEEE Transactions on Communications, vol. COM-20, n. 2, Abril 1972, pp. 190-195.

[15] J. S. Engel e M. M. Peristsky, "Statistically-Optimum Dynamic Server Assignment in Systems with Interfacing Server", IEEE Transactions on Communications, vol. COM-21, n. ${ }^{\circ} 11$, Novembro 1973, pp. 1287-1293.

[16] Y. Furuya e Y. Akaiwa, "Channel Segregation, A Distributed Channel Allocation Scheme for Mobile Communication Systems", Second Nordic Seminar on Digital Land Mobile Radio Communication, Stockholm, Suécia, Outubro 1986, pp. 311-315.

[17] J. H. Sanchez, "Traffic Performance of Cellular Mobile Radio Systems", PhD Thesis, University of Essex, Inglaterra, Julho 1988.

[18] L. Schiff, "Traffic Capacity of Three Types of Common-User Mobile Radio Communication Systems", IEEE Transactions on Communication Technology, vol. COM-18, n. 1, Fevereiro 1970. 
[19] D. C. Cox e D. O. Reudink, "Increasing Channel Occupancy in LargeScale Mobile Radio Systems: Dynamic Channel Reassignment", IEEE Transactions on Communications, vol. COM-21, n. 11 , Novembro 1973, pp. $1302-1306$.

[20] "Dynamic Frequency Allocation Increases Cellular Efficiency", Antennas Specialists, Communication Engineering International, Novembro 1986.

[21] K. W. Cattermole, M. D. Yacoub e D. M. Rodrigues, "Alternative Routing in Cellular Mobile Radio", Third UK Teletraffic Symposium, Colchester, Junho 1986, pp. 8-10.

[22] K. W. Cattermole e M. D. Yacoub, "Cellular Mobile Radio with Fuzzy Cell Boundaries", Fourth UK Teletraffic Symposium, Bristol, Maio 1987, pp. 17-19.

[23] M. D. Yacoub, "Mobile Radio with Fuzzy Cell Boundaries", Ph.D Thesis, University of Essex, Inglaterra, Abril 1988.

[24] B. Eklundh, "Channel Utilization and Blocking Probability in a Cellular Mobile Telephone System with Directed Retry", IEEE Transactions on Communications, vol. COM-34. n.. 4, Abril 1986, pp. 329-337.

[25] R. W. Lorenz, "Field Strength Prediction Method for a Mobile Telephone System Using a Topographical Data Bank", IEE Conference Publications 188 (Radio Spectrum Conservation Techniques), 1980, pp. 6-11.

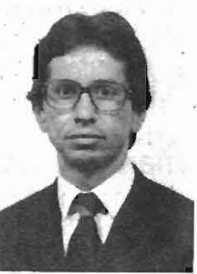

MICHEL DAOUD YACOUB graduou-se e obteve o grau de mestre na Faculdade de Engenharia Elétrica da UNICAMP, respectivamente em 1978 e 1983. Atuou no Departamento de Comutação do Centro de Pesquisa e Desenvolvimento (CPqD) da TELEBRÁS de 1978 a 1985, tendo trabalhado no desenvolvimento do sistema TROPICO de Comutação. Obteve o título de Ph.D. na University of Essex, Inglaterra, em 1988, desenvolvendo pesquisa na área de sistemas de comunicações móveis. Ingressou no Departamen to de Comunicações da Faculdade de Engenharia Elétrica da UNICAMP em 1988, onde atua como professor e desenvolve pesquisas na área de comunicações móveis, engenharia de desempenho, avaliação e simulação de tráfego. 